\title{
The Significance of Ethnography in Youth Participation Research: Active Citizenship in the UK after the Brexit Vote ${ }^{1}$
}

\author{
Shakuntala Banaji, Sam Mejias, \\ Benjamin De La Pava Velez
}

\begin{abstract}
In comparison to questionnaires, statistical analyses, interviews and experiments, ethnography tends to be a neglected method in youth participation research and in understanding political socialization and citizen action. This, we suggest, is very unfortunate. Where the concerns and experiences of researchers do not match those of young people, it is usually the young people's perspectives which remain outside the frameworks and conclusions. Drawing on original data and insights from two ethnographies of youth active citizenship initiatives in the UK - My Life My Say and Momentum - collected during a politically tumultuous 8-month period in 2017 , this article argues that ethnography has several advantages over other methods when it comes to understanding the depth and significance of youth civic participation and its links to peer groups and emotions. We contend that critical and reflexive ethnographies allow scholars and researchers to ask and probe young people's perceptions, opinions, actions and behaviours through the use of open-ended questions in settings where civic action is already taking place, thus triangulating findings in natural settings and building a sense of how communities of practice and activism function. In terms of ethics, voice and power, this ethnographic research approach gives young people more control over their own narratives about participation and affiliation in specific political or civic settings than surveys tend to do.
\end{abstract}

KEY WORDS ethnography; youth active citizenship; brexit; civic participation; Momentum

We seek interlocutors, not admirers; we offer dialogue, not spectacle. Our writing is informed by a desire to make contact, so that readers may become involved with words that came to us from them, and that return to them as hope and prophecy. (Galeano 1992: 140)

Sociální studia / Social Studies 2/2018. Pp. 97-115. ISSN 1214-813X.

1 The research reported in this paper was funded by the European Union Horizon 2020 Programme, "Constructing AcTiveCitizensHip with European Youth: Policies, Practices, Challenges and Solutions" (www.catcheyou.eu) Grant Agreement No. 649538. The views and opinions expressed in this publication are the sole responsibility of the authors and do not necessarily reflect the views of the Research Executive Agency of the European Commission. Additionally, we would like to thank all of our hosts and informants at MLMS and Momentum, UK, and all of the young campaigners and members who spoke to us so candidly over these past months. 


\section{Introduction}

Our cross-national, cross-disciplinary literature review for the "Constructing AcTive CitizensHip with European Youth (CATCH-EyoU)" project (Banaji et al. 2017) confirms that traditional studies of young people's civic and political participation include a high proportion of questionnaires, surveys and interviews, and to a lesser extent, observation and analysis of online data generated on Twitter and other social networking sites. Scholars such as Hoskins et al. (2015) have utilized cross-national surveys, while others such as Spannring, Wallace and Datler (2008), Keating (2015) and Sloam (2016) have measured young people's sense of national and regional identification and their learning experiences, concluding that young people's identification with the EU (Spannring et al. 2008), as well as their tendency to develop cosmopolitan dispositions (Keating 2015), can be correlated to their educational experiences; and that young people's political participation rates vary according to their country's civic-political cultures (Sloam 2016). Several of these conclusions offer valuable perspectives on the roles that factors such as education and community interactions play in young people's participation in political and social life. This allows scholars and activists working with young people to understand in greater depth the consequences of particular courses of action and the effectiveness of certain styles of communication on motivating civic behaviours. Over a century after Malinowski's (1989) contemptuous scrutiny of the Trobriand islanders as a subordinate "other", ethnography as a method, a methodology and an epistemology has undergone considerable upheaval, reflection and decolonial critique. Here, while also alert to its constraints, and to the significance of other methods, we highlight a selective outline of ethnography, demonstrating its aptness for our work with youth activists.

Funded by the EU Horizon 2020 Young 5a programme, CATCH-EyoU (2015-2018) aimed to identify factors, meanings and practices influencing different forms of youth civic and political engagement across Europe. The project included a consortium of eight participating universities in the Czech Republic, Estonia, Germany, Greece, Italy, Portugal, Sweden, and the UK, bringing together scholars from different disciplines: Psychology, Political Science, Sociology, Media and Communications, and Education. One of the most innovative research strands of the project was its in-depth ethnographic study of youth participation across the eight countries. Ethnography, still a neglected method in youth participation research, offers a way to capture the perspectives of young people that remain outside the frameworks and conclusions of a considerable portion of academic literature. Drawing on original data and insights from two ethnographies of youth active citizenship initiatives in the UK - My Life My Say and Momentum - collected during a politically tumultuous 8-month period in 2017, this paper argues that ethnography has several advantages over (and, more pertinently, when used alongside) other methods when it comes to understanding the depth and significance of youth civic participation and its links to peer groups and emotions. We contend that critical and reflexive ethnographies allow scholars and researchers to ask about and probe young people's perceptions, opinions, actions, and behaviours through open-ended questions in settings where civic action is already taking place, thus triangulating findings in natural settings and building a sense of how communities of practice and activism function. In terms of ethics, voice, and power, this approach gives 
young people more control over their own narratives about participation and affiliation in specific political or civic settings than surveys and questionnaires tend to do.

\section{Mapping the ethnographic turn: strengths and limitations of the research strategy}

Two independent developments gave rise to ethnography as a method(ology) during the late $19^{\text {th }}$ century and beginning of the $20^{\text {th }}$ (Atkinson, Coffey and Delamont 2011; Brewer 2000; Denzin and Lincoln 2005). On the one hand, British social anthropology - Malinowski, Pritchard and Radcliffe Brown to name a few — with its British colonialist drive to better understand those colonised, and on the other hand, the Chicago school of sociology — with scholars like Mead, Park and Burgess (cf. Bulmer 1984) — seeking to grasp the underbelly and underclass of the city and its phenomena. While the former discussed "ethnography" and the latter "participant observation", both approaches sought a level of rich, deep sociocultural description of people's life-worlds by spending considerable time ${ }^{2}$ with those under observation (usually considered "exotic", and/or "foreign"), taking notes along the way, not just of what people do, but also about why, where, with whom, and how they do it. Since then, the two approaches have diverged, with participant observation now considered one of several methods used in ethnographic research (Berg 1998; Brewer 2000). During this stage where positivism still governed the social sciences, particularly throughout Anglophone academia, two major critiques of ethnography emerged. First, questions arose about the reliability, validity, and replicability of ethnographic studies. Second, the apparent lack of "robust" theory building from ethnography led to the deriding of its contributions as "mere description" and/or common-sense repetition (see Glaser and Strauss 1967; Hammersley and Atkinson 2010; Hansen 1979; LeCompte and Goetz 1982). Embedded in these critiques were two factors that proponents of ethnography have now embraced as key elements of the research style: the researcher/author and the text. These have also become the two continued points of self-reflection, and are drivers of ethnography's epistemic value.

\section{Between researcher and researched: reflexivity and power}

First, a word on the role of the researcher. John Brewer succinctly notes that "[t]he natural science model of research does not permit the researcher to become a variable in the experiment, yet ethnographers are not detached from the research but, depending on the degree of involvement in the setting, are themselves part of the study or by their obtrusive presence come to influence the field" (2000: 20). The acknowledgement that introducing one (or several) external element(s) into a system changes it in both predictable and unforeseen ways might seem banal to some researchers, but from a positivist perspective, this is precisely what makes ethnography such a problematic endeavour, as objectivity,

In this context, this meant a minimum of six months, up to three years. Nowadays, for many reasons, it is often impractical to spend prolonged time at a study site, whether due to budgetary restraints, institutional barriers, or data privacy reasons. 
truth, and representativeness are thus impossible to attain. (For a critique of this critique, see Anderson 1978; Kuhn 1962; and Platt 1981.) It is possible to categorize the responses to this critique: On the one hand, there have been attempts to systematize and control the role of the researcher in the hope of being rigorous enough to attain the "truth" (see Athens 1984; Becker 1970; Bogden and Taylor 1975; Lofland 1974; Matza 1969; Seale 1999). On the other hand, there have been, from very early on, systematic critiques of the possibility of such a thing as the "detached positivist (male) observer" and the ideal of "truth extraction" (see Benedict 2005; Boas 1920; Dey 1993; Escobar 1998; Hammersley and Atkinson 2010; Santos 2010). Authors such as Ruth Benedict (ibid.) and Franz Boas (ibid.) advocate the inclusion of aesthetic and storytelling sensitivities in the writing of ethnographic texts. Thus, a response to the colonialist authority of the ethnographer has been, from the beginning, to recognise the affective, aesthetic such as and other sensibilities of researchers' and people's life-worlds, combining them into the text. We draw attention to this because the history of ethnography is not one of a simple linear development from positivism and colonialism to social constructionism and critical and interpretative frameworks (Atkinson et al. 2011). What is usually termed the post-structural/reflexive turn of the 1970s marks a shift from the idea of the researcher as observer to the researcher as a (politically) committed author, and this is of key importance for the research on civic and political activism amongst young people that we recount in later sections. It was imperative for researchers to become reflexive (Behar and Gordon 1995; Clifford and Marcus 1986; Enslin 1994; Geertz 1989; Hammersley and Atkinson 2010). Reflexivity, now considered a pivotal element of ethnography, called for an acknowledgement that neither researcher nor researched are empty vessels, but rather subjects with their own agendas and unequal positions. In turn, this begets further reflection on power relationships. A clear example of this is to think how one's age, gender, and ethnicity may hinder or provide advantages to investigating say, young people's subcultures, and might bias the kinds of questions asked in surveys.

Then, reports or scientific papers and the data the analyses in them are based on, are no longer reflections or an extract of "reality", but constructions, bound to power relationships of representation and interpretation. Clifford Geertz's (1973) concept of “thick description" refers to the inclusion, when writing, of the underlying patterns, context, codes, and internal hermeneutics of that which has been observed, and this includes the power relationships that enable such observation. The strength of Geertz's concept lies not just in understanding the difference between a blink and a wink, as famously summarised, but also in recognising and understanding why there was a wink/blink in the first place, with the researcher being able to observe it and why it may have been directed at the researcher her/himself or a person in their vicinity.

While it is unquestionably the case that the social science researcher's biases and beliefs, contexts and knowledge play a role in every kind of research including quantitative studies, and shape the instruments of research and the interpretations of data, the difference for the ethnography of today is that reflexivity is neither required systematically nor applied in large-scale survey research or experiments. The necessity for contextualisation of results, self-awareness, understanding of linguistic biases, and reflexivity, is often not even acknowledged in studies of (young people's) political socialisation that utilise experimental 
or other quantitative methods (Quintelier 2008; Torney-Purta, Wilkenfeld and Barber 2008). Indeed, it is acknowledged only fleetingly in many qualitative interview-based studies (Faas 2007; Flanagan et al. 2011; Kimberlee 2002). Without such an acknowledgement of the power and positioning of researchers and research participants in particular historical and social configurations, findings and conclusions are offered up as universally valid "truths" that shape the ways in which research subjects' subcultures, life-worlds, citizenship, activism, or other forms of social interaction are studied and theorised.

Accompanying the epistemological changes in ethnography, there have been several attempts to redress the balance of power in the production of knowledge through ethnography. These range from collaborative/public anthropology (Lamphere 2003; Lassiter 2005a, 2005b; Peacock 1997) and participatory action research/emancipatory research (Fals Borda and Rahman 1991; Freire 1990), to feminist and postcolonial contributions (Behar and Gordon 1995; Mbembé and Nuttall 2004; Mignolo 2011). The three defining characteristics of these attempts have been: (1) to advocate for the pleas and causes of those studied, whether it is through policy and/or co-writing the texts; (2) to reciprocate the help and collaboration provided by the subjects of study in a way, hopefully, that improves their living conditions; and, finally, (3) to privilege other ways of knowledge production, such as producing a film or an exposition of material culture.

From a positivist standpoint, the sample sizes used in ethnographic critiques of theorybuilding often fail to meet criteria for generalisation. However, positivist, universalist theory building is by no means the standard by which many ethnographers measure their work. Those partial to ethnography as a methodology have embraced the role of the researcher as an active participant as a unique way to combine academic rigour and research with politics and ethics.

In this section we highlighted the strengths and limitations of using ethnography as a research strategy. In the next section we discuss how ethnography has been used to study young people's political identities, and their sense of citizenship and civic participation.

\section{Ethnography about young people and citizenship}

Agency and belonging are central concerns of youth citizenship studies, with diverging, sometimes autonomous, sometimes institutional and normative understandings of what it means to be a citizen (Banaji et al. 2017). Using ethnography to research youth citizenship entails privileging, above all, the perceptions of what civic action means for young people, their practices and their beliefs. For the sake of clarity, the works reviewed here are divided, somewhat pragmatically, into those dealing with "civic" and "political" participation. We begin with research on the civic sphere, understanding these as primarily concerned with the different ways in which civic engagement and citizenship can be articulated.

In Rio de Janeiro, Brazil, Leticia Veloso (2008) asked children and teenagers from different socioeconomic backgrounds how they perceived themselves as "citizens with rights". This project was in the context of legislation that sought to help the most disadvantaged children receive care, support and have their needs fulfilled by recognising them as citizens. Veloso illustrated how this was lived out and appropriated in two contrasting examples: poor, mostly 
black, marginalised children who spent much of their time on the streets, and amongst a primary school class of mostly white children in the suburbs. While the former children learned about citizenship mostly through government and non-government programs, the latter had spaces in school reserved for them to learn how to become "responsible citizens". Using her observations of such distinctions in practice, Veloso argues "...there are profound differentiation processes determined mainly by class and race at play, with the result that, even though all children are now to be considered citizens, in effect some become, so to speak, "more citizens than others"" (Veloso 2008: 46). In another example from South America, María Claudia Villareal's (2015) work explores how indigenous teenagers from the qom/toba tribe living in Rosario, Argentina, manage their ethnic identities and their burgeoning political selves in three different scenarios: school workshops, local community elections and city-wide youth events. Documenting these youth's policy and political proposals, Villareal highlights the tension they experience between their identity as indigenous and as members of a wider non-indigenous place, between self-preservation (at points seen as self-isolation) and precarious integration. Thus, the focus of the qom/ toba youth is on ambitious policies that aim to recognise their duality as citizens while not excluding others or privileging themselves over others.

In Finland, Lappalainen (2014) contrasts the "ideal" normative Finnish and European citizens of school curricula and education policies with the lived experiences, expectations and perceptions of students of social services and health care in a Finnish higher education institution. Their choice of subject of study, as well as socioeconomic background, ethnicity, and life history affects the students' conception of themselves as European citizens and workers, as many do not consider having opportunities to travel, live, and work abroad. This suggests a disconnect, Lappalainen argues, between the construction in the abstract of citizenship in curricula or policies, and students' intersectional subjectivity. Similarly, Ribeiro et al. (Ribeiro et al. 2012; Ribeiro, Malafaia, Fernandes-Jesus, Neves and Menezes 2014) examine how migrant youth, parents, policymakers and teachers in Portugal perceive and have been affected by reforms in education pushing for "citizenship education". These studies highlight a disconnect between the ideas in the policies and the realities of schools and youngsters, which has partly to do with the conceptualisation of the role of the school in providing civic and citizenship engagement and the prejudices, exclusion, and discrimination students face in schools. In turn, this emphasises the lack of spaces and opportunities for civic engagement for young people. Often ignored as a factor in questionnaires, this absence of space and opportunity contributes to the narrative of youth as apathetic and uncommitted to (conventional forms of) politics. Finally, working with Bulgarian students in the UK, Elena Genova (2016) showcases how the demands of globalisation and neoliberal citizenship, flexibility/transnational mobility, cosmopolitanism, self-reliance, and individualism come to shape the interplay with the different identities her subjects can take on, depending on the context they are in: migrant, student, European, and Bulgarian (see also SlavtchevaPetkova and Mihelj 2013).

If the previous studies have focused on the possibilities youth have and seek to participate in their communities and as citizens, the other tendency has been to examine the difficulties some groups of young people face in doing so. Framed after the attacks of 9/11 in the United 
States and 7/7 in England, a number of studies have tried to investigate how security concerns and anti-terrorism policies have affected young Muslims' sense and practices of citizenship. Maira's (2009) ethnographic study claims that contexts position young British Muslims in a state of "precarious citizenship" as prejudice, fear, and unstable economic opportunities and positions hinder economic and social participation. Maira uses the term "dissenting citizenship" to highlight the ways in which youth articulate the demand for inclusion with the demand for the recognition of their cultural practices. This articulation contains several practices of political activism, media-savvy strategies of self-representation to combat stigma and misrepresentation, and community activities where faith and secularism intertwine.

Mustafa (2016) argues that one of the main problems facing young British Muslims is not their lack of sense of civic duty or political engagement as British, as Muslims, and as citizens, but the lack of efficiency their efforts tend to have as they are unceremoniously disregarded by policymakers and politicians as they do not engage in traditional forms of participation (e.g. party politics). The drive of her participants to engage in alternative forms of civic engagement derives from their active redefinition of what citizenship means. Working with young Australian Muslim citizens, Harris and Roose (2014) coin the term "DIY citizenship". They focus on the "middle of the pack" Muslim youth, highlighting how they prefer to associate themselves and partake in informal, localised, everyday efforts that prioritise a politics of self-actualisation and individual responsibility over traditional and overtly political organisations and initiatives.

All these studies, crucially, find that, generally, many young Muslims interlink their civic, political, and community engagement with their faith and its tenets to dispel negative stereotypes. The notion of Do-It-Yourself citizenship is one which might be seen as vehemently opposed to the highly normative definitions which emerge from and are used in measuring the civic participation of young people in studies such as Mahatmya and Lohman (2012) and Hoskins et al. (2015; see also Cicognani, Mazzoni, Albanesi and Zani 2015). However, to assume that all DIY citizenship is politically progressive would be naïve. Ethnographies (Grimm and Pilkington 2015; Koronaiou et al. 2015; Meuleman and Boushel 2014) can reveal how a feeling of rage and disillusionment over the economic crisis and the political system lead to racist, nativist, anti-immigrant protectionism and a disavowal of traditional forms of politics that lead to "consensus".

In addition to the key questions of longstanding civic participation studies about trust, democratic values, the loci of political socialisation, and the extent to which young people are rejecting institutional politics, the insights discussed above were at the forefront of our minds when selecting our cases and carrying forward our own ethnographic work for the project CATCHEyoU. Amongst other issues, we took into consideration the lack of spaces for engagement for minority ethnic and religious youth, as well as the dearth of alternative spaces and places for youth engagement; the attractiveness of authoritarian politics for some white youth who reject multiculturalism and tolerance as being associated with ethnic and economic decline; the need for an understanding of the role of emotion in political and civic motivation; and the role of the internet in communication for those outside institutional power. In the UK, this led us to choose two quite contrasting initiatives. The first, a politically centrist youth political participation NGO called My Life My Say, attempts 
to engage young people - including ethnic minorities - with institutional political activities, and to ensure that existing politicians are aware of young people's political concerns. The second, a cross between a grass-roots mobilisation organisation for an established political party and a left-wing social movement in its own right, Momentum, has emerged out of the profound dissatisfaction of left-wing young people with the state of the nation after a decade of austerity and cuts, and with the disconnected nature of parliamentary politics, but without rejecting democratic politics as a means of moving towards a fairer society.

\section{Methods}

For our ethnography, we conducted sustained reflection, participant observation, key informant interviews, and documentary and visual analysis of texts and physical materials. Our team of two researchers worked over time at both Momentum and My Life My Say. For a number of reasons, we elected to focus more of our observation and interview time on Momentum (35 observations, 23 interviews) than on My Life My Say (12 observations, 3 interviews). Firstly, Momentum was a larger organisation and granted us access to a busy daily office life with constant activity, whereas My Life My Say had no daily office life to speak of and its CEO did not have a set number of days in which he worked from their freelancer office. Secondly, and considering Momentum's position on the UK national stage, organisational reach, and aspirations to impact election outcomes, we felt that the announcement of a snap general election in 2017 gave us a unique opportunity to observe innovative forms of youth citizenship operating at the highest levels of UK politics. In the case of My Life My Say, their tendency to hold major (Parliamentary and European policymaker level) and minor (café workshops across the UK for 15-20 young people) public events afforded us a different kind of observation that richly amplified data collection.

In our day-to-day engagement during the ethnography, for Momentum we would typically arrive at the office unannounced and spend an hour sitting at a laptop, making notes, and observing the office at work. The remaining 3-6 hours that we spent at the office on any given observation day included directly volunteering for Momentum, or engaging in key informant interviews with office staff and volunteers (and taking field notes during breaks for both). Our observations of My Life My Say public events usually involved participating alongside audience members and taking field notes.

In addition to observations and interviews, we took photographs with permission at all observations and on a few occasions (e.g. a Momentum door knocking training event) shot video. We collected data from both organisations' websites, and Twitter, Instagram and Facebook platforms (screen shots); downloaded original videos produced by Momentum; tracked and collected all media coverage of both organisations throughout the period of the study; signed up for listservs and retained organisational emails to supporters; and collected or copied public and internal organisational documents (subject to permissions).

Our ethnographic code of ethics prioritised reciprocity when first approaching both organisations, by offering to provide a service to each organization that would be beneficial to their organisational missions. In the case of My Life My Say, it was agreed at the outset that LSE would lead on designing, implementing, analysing, and reporting a comprehensive 
research study to elicit and publicize youth views about Brexit, at no cost to My Life My Say. Momentum requested that as reciprocity for access to their organisations, all observations during the weeks leading up to the June 2017 general election be reciprocated in the form of campaign volunteering; during five weeks in May and June we spent 3-4 days per week volunteering on any and all campaign tasks assigned. Also at Momentum, a separate ethical reality confronted us at the outset of our research: staff members appeared to be wary of new people coming into the office and claiming that they were there to report on the organisation's activities. Prior to the beginning of our fieldwork, Momentum had been "infiltrated" by an undercover reporter from the UK Channel 4 news programme Dispatches, who had volunteered for months at Momentum while recording daily life on a camera that was fitted inside a coffee mug. Although the reporter's actions were discovered and the intent to "find dirt" on Momentum proved futile, this created an atmosphere of deep suspicion. Recognising this at the outset of our fieldwork, we took great care to announce our identities, roles, and working patterns during each visit, offering staff members opportunities to ask questions about our work or to be removed from any of our data collection activities. These actions when combined with our frequent presence as unpaid volunteers helped to build strong levels of trust.

\section{Young British activists and social change}

\section{Case study 1: Mapping horizontal leadership and action in national political campaigning}

In two years, Momentum has evolved from a loose collection of generally young individuals supporting Jeremy Corbyn's democratic socialist leadership of the Labour Party into a national movement with over 30,000 members and 170 local activist groups. Partly a political social network and partly a campaigning hub, we have watched Momentum reshape a significant aspect of national progressive politics in the UK. Most of Momentum's national office staff are under the age of 30, with key staff members in their late teens and early twenties.

When a general election was announced in late April, this was an ideal opportunity to learn while the organisation was trying to fulfil its core mission of electing Labour into power, and our research entailed nearly full time volunteer work at Momentum, working four days a week for the duration of the six week election campaign, performing any and all requested tasks (including texting supporters, promoting the campaign via social media, and troubleshooting administrative tasks at the office). During our observations over a period of eight months in 2017, we found that many Momentum staff personally knew Jeremy Corbyn, or were explicitly inspired by his political career. The combination of such personal connections, and the perceived political integrity of Corbyn's political positions and career, were key motivating factors.

The guy is just energetic and confident and Zen. He really has got this inner Zen about him. (5 June 2017 - Field notes: Comments by staff member during final national office team meeting before the 2017 election) 
The group's inception happened specifically to support Corbyn's leadership bid because it embodied a fresher, more egalitarian, and less neoliberal politics. It is therefore logical that the movement's members would feel loyalty for Corbyn. However, the affection we witnessed went beyond political loyalty: "Cool old man" Corbyn (as characterised by another staff member), his political approach of personal integrity and equity through social democracy, is a "brand" that the young people working at Momentum believe in, despite repeated attempts by media to undermine him and Momentum (Cammaerts et al. 2016). It is a kind of politics that we saw young people endorse at election rallies, and through their votes, in June 2017.

This flexible style of politics - a horizontal, non-hierarchical leadership and activism was observable in practice on a busy and politically resonant day, May $31^{\text {st }}, 2017$, in which Jeremy Corbyn's last-minute, same-day decision to attend and participate in the 2017 UK election leaders' debate added to an incipient alternative media narrative about Theresa May's weaknesses and Corbyn's strengths. Captured during participant-observation at Momentum the day's events offer a vivid illustration of Momentum's horizontalism, and the rapid "ideas-to-action" approach that became their hallmark amongst a plethora of successful campaign practices and social media campaigning.

Waiting for a new volunteer assignment, one of us reads the Guardian's live politics blog online, and sees some breaking news which we promptly announce aloud to the entire room: "Hey, did anybody see that Corbyn is actually going to be doing the debate tonight?" Several people express excitement, while a couple of others remark that Corbyn debating live is a "terrible idea". The discussion turns to whether Corbyn is setting himself up to be attacked by other politicians, or whether he might get credit for just showing up.

This snippet of information changes the course of the day's events at Momentum headquarters. Jim walks over and sits down with the media team to discuss how to shape the narrative response to Corbyn's participation in the debate, to send across Momentum's social media platforms. $\mathrm{He}$ semi-jokingly suggests doing a Facebook Live event with a cardboard cut-out of Theresa May, so voters could ask it questions. Everyone brainstorms response ideas.

Two hours later, a life-sized cut-out of Theresa May has been erected in the middle of the room and there's a firm plan for a response. Having been there at the inception of the idea, one of us is picked to go out to Euston station to help wrangle crowd involvement for a "vox pop" they had decided to shoot for a video that will be uploaded to social media just before the debate.

In the context of usually dull political reporting in the UK that is known to alienate young people, the concept is astute and amusing. Momentum hire a comedian and a cameraman to take the cutout to people on the street, inform them that Theresa May will not be attending the leaders' debate, and then give them an opportunity to tell the Prime Minister what they think about her. The resulting video, just over 100 seconds long, is blasted across Momentum's social media before and during the debate with the hashtag \#wherestheresa, a play on a children's activity storybook "Where's Wally?", and an example of $21^{\text {st }}$ century instant response campaigning, made for social media dissemination, and entirely designed by young people, for young people.

(31 May 2017, noon - Field notes: participant-observation as volunteers for Momentum's general election campaign) 
But what did we learn, and what of our role as researchers in that space? The fact that one of us as a researcher-volunteer was able to casually share important campaign news with an entire office full of alert young activists, and then to be selected for a role in the designated theatrical response, results from a combination of factors, starting with the absence of any punitive or regulated professional political campaign culture within the Momentum thinkspace, and including our unquestioned presence with the team as trusted researcher-activists present for several weeks of intensely emotional political activity. This trust had been built through weeks of regular volunteering in which we had clearly and frequently communicated the nature of our presence as researchers while demonstrating our commitment to providing authentic reciprocity through sustained volunteering. We'd watched the core team running horizontal conferences and workshops on galvanising new political ideas, motivating excluded communities, and explaining how to telephone hesitant voters; we'd witnessed their careful pedagogic approach as they set up elaborate "teachable" moments around mock-discussions on door-steps or responses to negative news stories. We were aware of the tensions between "old-style", somewhat rigid left-wing politics that offered commitment and energy but pushed for absolute political correctness, accuracy, and collective-speak on every position, and the gradual erosion of this mode via the enthusiastic and/or caustic responses of younger people with different experiences and ideas of what it means to be political and to want to fight for social justice. More to the point, we'd gotten beneath the skin of the pernicious notion that contemporary youth politics is all style and no substance, full of immature moaners, and that this is merely a "populist" group of cheer-leaders for a far-left has-been.

There was evident ideological commitment to social justice and equity on display in the months of our observations, and this permeated interpersonal interactions, gender issues, and the signs posted in the campaign kitchen, which remind people to do their own washing up - there were no cleaners. It was not, however, shoved down people's throats through patronising leaflets or newspapers. There were also (in our view, healthy) tensions on display. These were not always resolved in meetings and discussions. We noticed that there were power struggles (between old-timers and new recruits, the ones who control lists and the ones who approach new people through cold calling; those who want to plan and those who "just want to get things done"; the centralisers and the de-centralisers); and, despite the flat structures, there were expectations of hierarchy that had to be constantly undermined and unsettled without alienating those who felt that their raison d'être was under threat:

When I arrived at the office today, I saw the volunteer coordinator walking a new volunteer over to Felicity, a volunteer I had worked with the previous day, to ask if she needed any support. "Simon is here to help if you need it". The first thing Felicity said in response was not to Simon but looking past him to the volunteer coordinator: "You know yesterday we had five people sitting around a table working on this, and I got more done in two hours on my own today, so I think we need to be smart about how we're using everyone's time."

(11 May 2017, 11am - Field notes: participant-observation as volunteer for Momentum's general election campaign) 
Witnessing how these tensions are handled and defused allows us to listen "knowingly" to those who have legitimate critiques that have not as yet been taken on board: how to get more Black and minority ethnic voices to contribute significantly without being appropriated or tokenised; how to make it easier and more comfortable for young working class people to take a seat at the Momentum/Labour table when they have to be out there earning a living; how to communicate in a language which is not just for the socially committed urban left, and the digitally connected; how to recover quickly from the personal pain of biased negative news reporting.

Had we been researching the group through surveys or even through one-off interviews, it is entirely likely that we would have missed the nuance, build up, and intensely collaborative way in which practical and political ideas flew around and were put into action. But more importantly, there would not have been opportunity for the initial wariness to dissipate. Working alongside us for an extended period and doing life-narrative interviews in which extremely personal and cathartic details were shared with us had created a bond that could not be short-circuited through other approaches. With no erstwhile bosses, or official rules governing the use of time, social conversations during the workday were commonplace, and became a significant way in which we built trust with staff, and in which they bounced ideas off each other.

While our weeks of observations and interviews enriched our understanding of the political context and motivation as above, even a single vignette from ethnography can thus reveal the richness of citizenship processes occurring in the everyday lives of young people in a new-wave activist initiative. These cannot easily - if at all - be captured in their entirety through surveys, or even interviews: a truly active and influential youth citizenship, unconventional (in terms of horizontal, de-hierarchical methods) while also deeply "institutional" (in terms of its need for volunteers able to subsist without wages; general lack of ethnic diversity at the erstwhile top, despite starting in London; intended purpose: to spur voting for a large left-of-centre political party; and audience: the British public). It also suggests that Momentum's horizontal and flexible roles and practices, its collective imaginary, allied to meticulous data collection and analysis, had created a powerful platform for a political engagement strategy that could be deployed within hours, and instantly reach a national audience.

\section{Case study 2: Creating spaces for young people's voices on Brexit}

Our second ethnographic site, the youth political participation NGO My Life My Say (MLMS), is the organisational vehicle for a young London politician to involve more young people - and in particular those from ethnic minority communities - in institutional politics in the UK. The organisation's Chief Executive is a Labour party councillor for the London borough of Hackney, and was elected to office in 2013 at the age of 21. Started in 2015, MLMS is now staffed by the CEO and 2-3 part-time workers. Prior to the EU referendum in July 2016, its work consisted mainly of EU and Starbucks-funded "Café Europe" events that would invite young people to discuss politics over free coffees. After the Brexit vote, MLMS changed their focus to explore and organise youth action to get youth 
views considered during the Brexit negotiations. Over a twelve-month period, we observed MLMS' efforts to engage young people in detailed political discussions about Brexit through cafés and other public events; to use its networks to create a platform for bringing attention to youth views on Brexit through its parliamentary group; and to participate through its CEO in public speaking, lectures, and political discussion events across London and the UK. They worked with Parliamentarians to establish an All Party Parliamentary Group (APPG) on a Better Brexit for Young People; began holding "Brexit cafes" to encourage young people across the UK to discuss the future of the UK after Brexit; and in 2017 they launched a political campaign to increase youth awareness of and participation in shaping post-Brexit British policy and politics.

The event starts at 6:30 pm, first hour spent socializing in a party-type space. It has the feel of an art gallery opening, with low lighting and chairs set against the wall. This is a multicultural audience with mostly black and brown young people here. There is no seating except at edges of the room. In the centre, there are round standing tables. The MC announces that the tables with the whiteboards on them to write what people think about Brexit. At the front of the room is the stage area with a microphone and speakers. The event's host is a young person who started a charity dedicated to giving Black university students in Bristol a voice. The event has been billed in advance by MLMS as a night of "TEDx-style speeches and breakout debate sessions, along with spoken word, poetry and comedy performances".

The host introduces the night, encourages audience to Tweet, using a Snapchat filter. She introduces the first performer, a young black female who performs an original poem called "Who will give her a voice?" It's really good, very Brexit focused, a rallying cry to include young marginalised voices in conversations about political events that will affect young lives, and it's also pretty angry. She is talking about the experience of marginalised women of colour, and connecting it to the Brexit-Leave campaign's scapegoating of refugees and migrants. It is excellent. There are probably 200 people here now. After the poem, MLMS's CEO delivers a speech. He comes across as committed to making sure that young marginalised people are involved in political decision-making. It's at the heart of what he is talking about - getting young people like those in the room with us, from different ethnicities and cultures, involved in politics to make a positive change in the world. Nevertheless, hard to tell what levels of marginalisation are represented by those present.

He mentions the parliamentary group on youth Brexit views that he has started, and directly name checks me and the LSE as working on a report that will be launched later in the year that brings young people's views on Brexit to the highest levels of UK government and EU policymakers. This is familiar, and reflects the value that our research collaboration has added to their work. In return for being ethnographic subjects we are conducting free research for them, and he has eagerly used the LSE brand to legitimise his work and impress politicians and policymakers.

Later in the night, the MC explains that "before we go into our TEDx-style talks, we're going to have some discussion at our table". Discussion questions come up on the projector screen:

"Do you think we'll eventually be trying to re-enter the EU?"

"Do you think young people's views were taken into consideration?" 
She says, "In five minutes we'll take some responses." There is a lively buzz around the room, and most of the conversations have politics at their core.

(12 April 2017 - Public launch of "The Better Brexit" campaign, held at a local social venue in East London)

Despite its formal affinities with business networking events and the centrality of individual charisma in driving the agenda of the organisation, the event exemplifies MLMS' efforts to create inclusive spaces for young people to share their own stories, creative expressions, and thoughts about Brexit. It shows how the creation of interactive youth spaces around specific political issues can feed into motivation to participate on a range of political issues. MLMS' inclusion of an audience discussion and feedback session in particular offers an unusually participatory and reflexive forum within an event style that would normally follow a performer-audience dynamic. However, it also reveals the challenge of fostering meaningful political debate when emotions about politics are running high. The event's London location and networks gave it a distinctly pro-EU and pro-Remain feel. While this is to be expected considering London's cosmopolitan outlook and British young people's general preference to remain in the EU, and was explicitly addressed by including pro-Leave performers, it still nonetheless created an atmosphere of too-easy consensus that would have alienated working class Leavers from smaller towns outside the metropolis. There were clear examples of Maira's (2009) "dissenting citizenship" since the night involved numerous black and brown young people explicitly and publicly articulating their need to be included and recognised in the Brexit negotiations process.

Our case studies demonstrate the possibility of using ethnography not only to nuance and record organic active citizenship processes, but also to elucidate the effects of the researcher's positioning on the timing, nature, and complexity of the information available in the field of study (Brewer 2000). The researcher's agency and political values interact with circumstances in driving insightful interpretations in different directions: in this instance, unlike those who research communities of far right activism, we frequently found ourselves in agreement with the values of the organisations we were researching. We had to work all the harder to note moments of rupture or tension, and to trace the origins of these amongst young activists we had grown to like and respect. Our work provides a critical means of fusing political solidarity with academic research, and offers examples of how an ethically-driven approach to research partnership can generate insight.

\section{Conclusion}

The combination of methods from interviewing and observation to document analysis, utilised reflexively, alongside a long period of sustained contact, means the ethnographer is in a privileged position. This position is that of introducing complexity and nuance to common-sense assumptions, patterns, or correlations assumed prior to, and also during, fieldwork. This is because through ethnography, it is possible to understand internal divergence within a pattern, and the patterns within divergences. Further, ethnography as a methodology in examining relationships of groups, such as young people, to identities 
or positionings such as citizenship, invites a deeper, richer understanding of relationships with learning, with place, with peers, with institutions (in the broad sense of the term). It challenges scholars to think through how these relationships, attitudes, internal contradictions, practices, and beliefs come to constitute a sense of self, of community, and of belonging, and lead to particular forms of action or inaction vis-à-vis the state and the community. Thus, paraphrasing Clifford Geertz (1973), "little things speak of greater ones".

In light of the commitment and the flexibility it requires in terms of time, and the extent of access required to potentially controversial field sites, ethnography tends to be a neglected method in youth participation research compared to questionnaires, statistical analysis, interviews, and experiments. Although, as our article has demonstrated, there are clear advantages to its uses in such contexts, there remain barriers and weaknesses in ethnographic methods. For example, our study found that ethnography requires a high level of interpersonal interaction between researchers and subjects that must not only navigate the context of the researcher-researched relationship, but must also rely on effective informal social engagement. In other words, it is not possible to simply turn up at a site of fieldwork and get good data; one must continually make efforts at interaction to develop relationships that will yield the types of exploratory, learning interviews and discussions that provide deep insight into the culture, values and ways of knowing at youth participation organisations.

In work that engages with political activism through ethnographic methods, disenchantment with traditional and institutional form of politics continues to emerge as a significant finding. This is nuanced by an increased recognition of emotions as playing a contributing factor in young people's political engagement that emerges from participant observation and interviews. Our analysis of participant observations and interviews with young British activists confirms that critical and reflexive ethnography allows scholars and researchers to probe young people's perceptions, opinions, actions, and behaviours through openended questions in settings where civic action is already taking place and has already been categorized multiple times by scholarly schema or by journalistic reporting. We triangulated findings in natural settings, building a sense of how communities of practice work, and how activism functions, and providing evidence to nuance and critique both scholarly and journalistic accounts of youth apathy and lack of participation in politics.

Far from being a populist leader drawing young people to politics through sheer charisma, we discovered in one case how the rather low key and humble Jeremy Corbyn had become the human metaphor for the politics of fairness and respect that young people had been seeking and failing to find in previous years. In the other case, Brexit was the metaphorical straw that broke the camel's back, urging young people to reassess - and publicly critique a decade of excruciating austerity, underfunding, anti-youth policies, and anti-migrant politics from major political parties and the media. In terms of ethics, voice, and power, our research gave young activists more control over their own narratives about participation, affect, motivation, and affiliation in specific political or civic settings than the questionnaires that we were doing in parallel or than the British media does. As such, our ethnography provides future researchers with insights into the shared experiences of youth citizenship within activist initiatives, networks, and groups, and the social boundaries, definitions, symbolic bonds, and organizational roles or metaphors which motivate and scaffold individual active 
citizenship now and in the future. In Galeano's (1992: 140) words, our writing is driven "by a desire to make contact so that readers may become involved with words that came to us from [young people], and that return to [young people] as hope and prophecy".

\section{References}

ANDERSON, Digby. 1978. "Some Organisational Features of the Local Production of a Plausible Text". The Philosophy of the Social Sciences 8(2): 113-135.

ATHENS, Lonnie. 1984. "Scientific Criteria for Evaluating Qualitative Studies.” Pp. 259-268 in Studies in Symbolic Interactionism, Volume 5, edited by Norman K. DENZIN. Greenwich, CT: JAI Press.

ATKINSON, Paul, Amanda COFFEY and Sara DELAMONT. 2011. "Ethnography: Post, Past, and Present." Pp. 461-471 in SAGE Qualitative Research Methods, edited by Paul ATKINSON and Sara DELAMONT. Thousand Oaks: SAGE.

BECKER, Howard. 1970. Sociological Work. Chicago: Aldine de Gruyter.

BEHAR, Ruth and Deborah A. Gordon. 1995. Women Writing Culture. Los Angeles: University of California Press.

BENEDICT, Ruth. 2005. Patterns of Culture. Boston: Houghton Mifflin.

BERG, Bruce. 1998. Qualitative Research Methods for the Social Sciences. Boston: Allyn and Bacon.

BLUMER, Herbert. 1969. Symbolic Interactionism: Perspective and Method. Englewood Cliffs, N.J.: Prentice-Hall.

BOAS, Franz. 1920. „The Methods of Ethnology.” American Anthropologist. Wiley/American Anthropological Association.

BOGDEN, Robert and Steven Jay TAYLOR. 1975. Introduction to Qualitative Research Methods. New York: Wiley.

BREWER, John D. 2000. Ethnography. Philadelphia, PA: Open University Press.

BULMER, Martin. 1984. The Chicago School of Sociology: Institutionalization, Diversity, and the Rise of Sociological Research. Chicago: Chicago University Press.

CAMMAERTS, Bart, Brooks DECILLIA, Joao VIERA MAGALHÃES and Cesar JIMÉNEZMARTÍNEZ. 2016. Journalistic Representations of Jeremy Corbyn in the British Press: From Watchdog to Attackdog. London: LSE.

CICOGNANI, Elvira, Davide MAZZONI, Cinzia ALBANESI and Bruna ZANI. 2015. "Sense of Community and Empowerment among Young People: Understanding Pathways from Civic Participation to Social Well-Being." VOLUNTAS: International Journal of Voluntary and Nonprofit Organizations 26(1): 24-44.

CLIFFORD, James and George MARCUS. 1986. Writing Culture. Berkeley: University of California Press.

DAWSON, Andrew, Jenny L. HOCKEY and Allison JAMES. 1997. After Writing Culture: Epistemology and Praxis in Contemporary Anthropology. London: Routledge.

DENZIN, Norman and Yvonne LINCOLN. 2005. "Entering the Field of Qualitative Research." In The SAGE Handbook of Qualitative Research, 3rd ed., edited by Norman K. DENZIN and Yvonna S. LINCOLN. London: SAGE.

DEY, Ian. 1993. Qualitative Data Analysis. London: Routledge.

ENSLIN, Elizabeth. 1994. "Beyond Writing: Feminist Practice and the Limitations of Ethnography." Cultural Anthropology 9(4): 537-568.

ESCOBAR, Arturo. 1998. La invención del tercer mundo: Construcción y Deconstrucción del Desarrollo. Bogotá: Norma. 
FALS BORDA, Orlando. 1979. El problema de cómo investigar la realidad para transformarla. Bogotá: Tercer Mundo.

FALS BORDA, Orlando and Mohammad Anisur RAHMAN. 1991. Action and Knowledge: Breaking the Monopoly with Participatory Action Research. New York: Apex Press.

FOLEY, Douglas and Angela VALENZUELA. 2005. "Critical Ethnography: The Politics of Collaboration." Pp. 217-234 in The SAGE Handbook of Qualitative Research, 3rd ed., edited by Norman K. DENZIN and Yvonna S. LINCOLN. Thousand Oaks, CA: SAGE.

FREIRE, Paulo. 1990. Pedagogy of the Oppressed. Harmondworth: Penguin.

GALEANO, Eduardo. 1992. We Say No: Chronicles, 1963-1991. New York: W. W. Norton.

GEERTZ, Clifford. 1973. The Interpretation of Cultures: Selected Essays. New York: Basic Books.

GEERTZ, Clifford. 1989. Works and Lives: The Anthropologist as Author. Stanford: Stanford University Press.

GENOVA, Elena. 2016. "To Have Both Roots and Wings: Nested Identities in the Case of Bulgarian Students in the UK." Identities 23(4): 392-406.

GLASER, Barney G. and Anselm L. STRAUSS. 1967. The Discovery of Grounded Theory: Strategies for Qualitative Research. Chicago: Aldine de Gruyter.

GRIMM, Robert and Hilary PILKINGTON. 2015. "Loud and Proud': Youth and the Politics of Silencing." The Sociological Review 63(2_suppl): 206-230.

HAMMERSLEY, Martin and Paul ATKINSON. 2010. Ethnography: Principles in Practice. New York: Routledge.

HANSEN, Judith. 1979. Sociocultural Perspectives on Human Learning: An Introduction to Educational Anthropology. Englewood Cliffs, N.J.: Prentice-Hall.

HARRIS, Anita and Joshua ROOSE. 2014. "DIY Citizenship amongst Young Muslims: Experiences of the 'Ordinary'." Journal of Youth Studies 17(6): 794-813.

HEMMENT, Julie. 2007. "Public Anthropology and the Paradoxes of Participation: Participatory Action Research and Critical Ethnography in Provincial Russia." Human Organization 66(3): 301-314.

HOSKINS, Bryony, Michaela SAISANA and Cynthia M.H. VILLALBA. 2015. "Civic Competence of Youth in Europe: Measuring Cross National Variation Through the Creation of a Composite Indicator." Social Indicators Research 123(2): 431-457.

JOHNSON, Sarah K., Jennifer P. AGANS, Michelle B. WEINER and Richard M. LERNER. 2014. "Profiles of Civic Engagement across Educational Transitions: Stability and Change." International Journal of Developmental Science 8(3-4): 81-93.

KORONAIOU, Alexandra, Evangelos LAGOS, Alexandros SAKELLARIOU, Stellios KYMIONIS and Irini CHIOTAKI-POULOU. 2015. "Golden Dawn, Austerity and Young People: The Rise of Fascist Extremism among Young People in Contemporary Greek Society." The Sociological Review 63(2_suppl): 231-249.

KUHN, Thomas. 1962. The Structure of Scientific Revolutions. Chicago: University of Chicago Press.

LAMPHERE, Louise. 2003. "The Perils and Prospects for an Engaged Anthropology: A View From the United States." Social Anthropology 11(2): 153-168.

LAPPALAINEN, Sirpa. 2014. "Locality, Mobility and Labour Market Citizenship: Reflections of Finnish Vocational Students in Social Services and Health Care.” Pedagogy, Culture \& Society 22(3): 425-445.

LASSITER, Luke E. 2005a. "Collaborative Ethnography and Public Anthropology." Current Anthropology 46(1): 83-106.

LASSITER, Luke E. 2005b. The Chicago Guide to Collaborative Ethnography. Chicago: Chicago University Press.

LECOMPTE, Margaret and Judith P. GOETZ. 1982. "Problems of Reliability and Validity in Ethnographic Research." Review of Educational Research 52(1): 31-60. 
LOFLAND, John. 1974. “Analysing Qualitative Data: First Person Accounts.” Urban Life and Culture 3: 307-309.

MAHATMYA, Duhita and Brenda J. LOHMAN. 2012. "Predictors and Pathways to Civic Involvement in Emerging Adulthood: Neighborhood, Family, and School Influences." Journal of Youth and Adolescence 41(9): 1168-1183.

MALINOWSKI, Bronislaw. 1989. A Diary in the Strict Sense of the Term. Stanford: Stanford University Press.

MARR MAIRA, Sunaina. 2009. Missing: Youth, Citizenship, and Empire after 9/11. Durham, NC: Duke University Press.

MATZA, David. 1969. Becoming Deviant. Englewood Cliffs, N.J.: Prentice-Hall.

MBEMBÉ, Achille and Sarah. NUTTALL. 2004. "Writing the World from an African Metropolis." Public Culture 16(3): 347-372.

MEULEMAN, Bram and Corra BOUSHEL. 2014. "Hashtags, Ruling Relations and the Everyday: Institutional Ethnography Insights on Social Movements." Contemporary Social Science 9(1): 49-62.

MIGNOLO, Walter. 2011. The Darker Side of Western Modernity: Global Futures, Decolonial Options. Durham, NC: Duke University Press.

MUSTAFA, Anisa. 2016. "Active Citizenship, Dissent and Civic Consciousness: Young Muslims Redefining Citizenship on Their Own Terms." Identities 23(4): 454-469.

PEACOCK, James L. 1997. "The Future of Anthropology." American Anthropologist 99(1): 9-17.

PLATT, Jennifer. 1981. "The Social Construction of 'Positivism' and its Significance in British Sociology.” In Practice and Progress: British Sociology 1950-1980, edited by Philip ABRAMS, Rosemary DEEM, Janet FINCH and Paul ROCK. London: Allen and Unwin.

RIBEIRO, Norberto, Carla M. ALMEIDA, Maria FERNANDES-JESUS, Tiago NEVES, Pedro D. FERREIRA and Isabel MENEZES. 2012. "Education and Citizenship: Redemption or Disempowerment? A Study of Portuguese-Speaking Migrant (and Non-Migrant) Youth in Portugal." Power and Education 4(2): 207-218.

RIBEIRO, Norberto, Carla M. Almeida, Maria FERNANDES-JESUS, Tiago NEVES and Isabel MENEZES. 2014. "Europe as a Beacon of Democracy? Citizenship Policies Relating to Youth and Migrants in Portugal." Journal of Civil Society 10(1): 51-68.

SANTOS, Boaventura De Sousa. 2010. Descolonizar el saber, reinventar el poder. Montevideo: Trilce ediciones.

SEALE, Clive. 1999. The Quality of Qualitative Research. London: SAGE.

SKEGGS, Beverley. 1994. "Situating the Production of Feminist Ethnography." In Researching Women's Lives, edited by Mary MAYNARD and June PURVIS. Basingstoke: Taylor \& Francis.

SLAVTCHEVA-PETKOVA, Vera and Sabina MIHELJ. 2013. "Europe - A Default or a Dream? European Identity Formation among Bulgarian and English Children.” Ethnicities 13(5): 565-583.

SNELL, Patricia. 2010. "Emerging Adult Civic and Political Disengagement: A Longitudinal Analysis of Lack of Involvement with Politics." Journal of Adolescent Research 25(2): 258-287.

VAN MAANEN, John. 1988. Tales of the Field: On Writing Ethnography. Chicago: Chicago University Press.

VELOSO, Luis. 2008. “Universal Citizens, Unequal Childhoods: Children's Perspectives on Rights and Citizenship in Brazil." Latin American Perspectives 35(4): 45-59.

VILLARREAL, María C. 2015. Jóvenes indígenas y cultura política. Buenos Aires: CLACSO. 


\section{Authors}

Shakuntala Banaji is Associate Professor, Director of Graduate Studies and Programme Director for the MSc in Media, Communication and Development in the Department of Media and Communications at the London School of Economics and Political Science. Her books include The civic web: Young people, the internet and participation (MIT Press) and Children and media in India: Narratives of class, agency and social change (Routledge). Contact: s.banaji@1se.ac.uk

Sam Mejias is Researcher in the Department of Media and Communications at the London School of Economics and Political Science and Co-investigator on the Wellcome Trust (UK) and National Science Foundation (US) funded project "Science Learning Plus: Creativity and Equity in STEM Learning", where he conducts ethnographies of youth creative media learning practices. His research explores epistemic links between media, social justice, education and politics.

Contact: s.mejias@1se.ac.uk

Benjamín de la Pava Vélez is Anthropologist/Sociologist from Universidad Nacional de Colombia and holds a MSc in Culture \& Society (Sociology) and a PhD Media \& Communications from the London School of Economics and Political Science. He's currently Associate Professor at the Universidad Jorge Tadeo Lozano.

Contact: Benjamin.dlpvelez@utadeo.edu.co 